\title{
Cast Present Or Absent
}

National Cancer Institute

\section{Source}

National Cancer Institute. Cast Present Or Absent. NCI Thesaurus. Code C74763.

The determination of the presence or absence of casts in a sample. 